\title{
Late Morbidity among Survivors of Childhood Cancers; Experience at Tertiary Care Cancer Hospital
}

\author{
Najma Shaheen, Mir Rooh Ullah Jan, Shazia Riaz, Muhammad Saghir Khan \\ Department of Pediatric Oncology, Shaukat Khanum Memorial Cancer Hospital and Research Centre, \\ Lahore, Pakistan
}

Received: 02 March 2020/Accepted: 12 May 2020

\section{Open aCCess \\ Correspondence: Mir Rooh Ullah Jan, 7A Block R-3, Phase 2, M.A. Johar Town, Lahore, Punjab 54782, Pakistan. \\ Email: hellodr.soul@gmail.com}

Citation: Shaheen N, Jan MR, Khan S, Riaz S. Late morbidity among survivors of childhood cancers; experience at tertiary care cancer hospital. J Cancer Allied Spec [Internet]. 2020 May12 6(2):e1002957. https://doi.org/10.37029/jcas. v6i2.351

Copyright: (c) 2020 Shaheen, et al. This is an open access article distributed under the terms of the Creative Commons Attribution License, which permits unrestricted use, distribution, and reproduction in any medium, provided the original author and source are credited.

Funding: Nil.

Competing interests: Nil.

\section{Abstract}

Background: Long-term survivors of childhood malignancies are at increased risk of experiencing treatment-related morbidities. Survival into late adulthood in these children provides ample time for the acquisition of long-term sequelae. This study aimed to determine the late adverse effects among long-term survivors of childhood cancer from a low-income country perspective. Materials and Methods: Data were retrospectively collected from review of charts of patients aged under 18 years at the time of their primary diagnosis between 1 January, 1995, and 31 December, 2008, and who survived for at least 5 years after completion of their treatment. Analysed data included demographics, cancer type, treatment modality, types of chemotherapy agents administered and specific late morbidities including frequency of azoospermia, oligospermia, endocrine abnormalities, hearing and pulmonary function impairment and cardiac dysfunction among the long-term survivors of cancer. Results: The total number of patients was 300 with a mean age of $18 \pm 2$ years. The male to female ratio was 2.7:1. Median follow-up duration was 18 years (range: 5-25 years). Seventy-seven percent of patients were from Punjab, 20\% were from Khyber Pakhtunkhwa and $3 \%$ were from other provinces. Fifty percent had a diagnosis of Hodgkin lymphoma, $17 \%$ had acute lymphoblastic leukaemia, 13\% had non-Hodgkin lymphoma, 10\% had germ cell tumours and 10\% had other tumours. Fiftyseven percent received chemotherapy, 23\% had chemotherapy and radiotherapy, 15\% had chemotherapy and surgery, 3\% had chemotherapy, surgery and radiotherapy and $2 \%$ had only surgery. Notable long-term documented sequelae were; azoospermia/oligospermia in 64\%, endocrine abnormalities in $25 \%$ with hypothyroidism in $13.5 \%$ and follicle-stimulating hormone and luteinizing hormone abnormalities in $11.5 \%$, ototoxicity in $6.5 \%$, impaired pulmonary function tests in $4.6 \%$, cardiotoxicity in $2.4 \%$ and second malignancies (acute myeloid leukaemia and myelodysplastic syndrome) in $1 \%$. Conclusion: Childhood cancer survivors are at increased risk of adverse treatment-related sequelae and a long-term follow-up plan should be in place in centres where they receive treatment for their primary disease.

Key words: Hodgkin lymphoma, leukaemia, morbidity, neoplasm, paediatrics, retinoblastoma 


\section{Introduction}

The combined 5-years overall survival of childhood cancer is around $80 \% .{ }^{[1]}$ Further improvement in survival is anticipated due to the continuing refinement of treatment modalities and improved supportive care. Children have an increased number of days to live after the successful treatment of their primary cancer. As a result, they have an increased chance of manifesting long-term complications of primary cancer and its treatmentrelated sequelae. ${ }^{[2]}$

The primary treatment depends on the diagnosis and generally includes a combination of chemotherapy drugs with or without radiotherapy and surgery. ${ }^{[3]}$ The type of long-term sequelae to which these survivors are prone partly depends on the combination of chemotherapeutic agents and adjuvant therapy including surgery and radiotherapy. ${ }^{[2,3]}$ Adverse effects of cancer and its treatment in long-term survivors are a well-known phenomenon based on studies from the highincome countries. ${ }^{[4]}$ However, there has been limited research from low-income countries and the estimation of late adverse effects among survivors of cancer in low-income countries is usually an extrapolation from the results based on studies from the high-income countries. Disease nature, patient characteristics and socio-economic factors are different in low-income countries than those in high-income countries and, therefore, local studies are needed to truly estimate the burden of late complications in survivors of cancer in our population. ${ }^{[5]}$

This study aimed to determine the late adverse sequelae among long-term survivors of childhood cancer from a low-income country perspective.

\section{Materials and Methods}

This was a retrospective chart review of data from the electronic record of patients under 18 years of age who got treatment for their cancer at Shaukat Khanum Memorial Cancer Hospital and Research Centre from 1 January, 1995, to 31 December,
2008. After approval from the institutional review board, patients who fulfilled the following criteria were included for analysis;

- Treated with chemotherapy and/or radiation and/or surgery

- $\quad$ Five years or more post-primary diagnosis; and

- Follow-up in surveillance long-term follow-up clinic (LTF).

Data were analysed to determine each candidate's clinical and demographic characteristics, diagnosis, sex, age at the time of diagnosis, current age and survival duration since diagnosis and the type of therapy they received. Hodgkin lymphoma was treated with cyclophosphamide, vincristine, prednisone, dacarbazine/adriamycin, bleomycin, vinblastine and dacarbazine (ABVD) (cyclophosphamide, vincristine, prednisolone, adriamycin, bleomycin and vinblastine), OEPA/ABVD (vincristine, etoposide, prednisone and ABVD) or chlorambucil, vinblastine, procarbazine and prednisolone (CHLVPP)/ABVD (chlorambucil, vinblastine, procarbazine, doxorubicin, bleomycin, vincristine and etoposide). Burkitt lymphoma was treated as per UKCCSG NHL 2003 guidelines. [6,7] Acute lymphoblastic leukaemia patients received chemotherapy as per MRC UKALL XI/MRC ALL97 and UKALL 2003 guidelines. ${ }^{[8,9]}$ Retinoblastoma was treated with JOE chemotherapy (vincristine, etoposide and carboplatin). ${ }^{[10]}$ Germ cell tumours were treated with JEB (carboplatin, etoposide and bleomycin) or BEP chemotherapy (cisplatin, etoposide and bleomycin). ${ }^{[11]}$ Wilms tumour cases received chemotherapy as per children's cancer and leukaemia group and COG's Wilms tumour guideline (including nephrectomy, chemotherapy with or without radiation depending on risk group). ${ }^{[12,13]}$ Radiotherapy was given as per EuroNet radiotherapy guidelines in Hodgkin lymphoma, MRC UKALL XI/MRC ALL97 in acute lymphoblastic leukaemia and UKCCSG in retinoblastoma and Wilms tumour. ${ }^{[14-16]}$ 
The modalities used for detecting late adverse sequelae were; echocardiography for cardiac dysfunction, serum thyroid-stimulating hormone (TSH), free T4, testosterone, follicle-stimulating (FSH) and luteinizing hormone (LH) levels for endocrine abnormalities, seminal microscopy for sperm count, pure tone audiometry for hearing assessment and diffusing lung capacity for carbon monoxide (DLCO) for pulmonary function abnormalities.

Azoospermia was defined as the total absence of sperms from the ejaculate under the light microscope. Oligospermia was defined as sperm count $<20 \times 10 \% \mathrm{~mL}$ in the ejaculate under the light microscope. Ototoxicity was defined as an abnormal audiometric assessment of any degree according to the World Health Organization (WHO) classification of hearing impairment. ${ }^{[17]}$ Cardiomyopathy was defined as a fractional shortening of $<28 \%$ or ejection fraction $<55 \%$ or a decline of more than $10 \%$ over any interval of time with or without associated symptoms. Abnormal pulmonary function tests were defined as the DLCO $<80 \%$ from the predicted normal values for age and sex according to the American Thoracic Society guidelines. ${ }^{[18]}$ Hypothyroidism was defined as lower than the normal age-adjusted values of Free T4 with or without elevated TSH for age and gender. ${ }^{[19]}$

Toxicity evaluations were tailored according to the specific therapeutic exposures. Microscopic semen analysis was performed to determine azoospermia or oligospermia in children $>13$ years of age who received procarbazine. Serum $\mathrm{FSH}, \mathrm{LH}$ and testosterone levels were measured in those with azoospermia or oligospermia. Ejection fraction and fraction shortening as determined by echocardiography were used to evaluate cardiac dysfunction in children who received anthracyclines. Thyroid profile with T4, free T4 and TSH was used to determine thyroid status in children who received radiation to the neck. The audiometric examination was used to determine hearing dysfunction and DLCO to evaluate pulmonary dysfunction in survivors who received platinum-based chemotherapy or bleomycin. Hepatitis serology with HBsAg/Anti$\mathrm{HBs} /$ Anti-HCV was used to screen for hepatitis B and $C$ in all patients and if positive, polymerase chain reaction was done to confirm the diagnosis. The frequency of toxicities attributed to radiation and chemotherapy agents was separately calculated. All patients were followed in late effects clinic according to institutional guidelines.

Statistical analysis was performed using SPSS software (Version 20.0; SPSS, Chicago, IL). Descriptive statistics were reported as frequencies and percentages for quantitative data. The Chisquare test was used to calculate $P$-value for the determination of association between demography of the participants and the risk of acquisition of late adverse sequelae.

\section{Results}

The total number of patients included in the present investigation was 300. Among these, there were $73 \%$ males. The mean age of study population was $18 \pm 2$ years. The median follow-up duration was 18 years (range: $5-25$ years). Summary of these results, along with details of demographics of the cohort are given in Table 1.

Fifty percent of the survivors had the diagnosis of Hodgkin lymphoma at the time of their initial presentation [Table 2]. The most common treatment modality was chemotherapy alone (57\%), followed by chemotherapy and radiotherapy (23\%) and chemotherapy and surgery (15\%) [Table 3]. The most commonly used chemotherapeutic agents were anthracycline (81\%; 100-400 mg/m²), bleomycin (52\%; 61-118 $\left.\mathrm{mg} / \mathrm{m}^{2}\right)$, procarbazine (48\%) and etoposide (17\%; $500-2000 \mathrm{mg} / \mathrm{m}^{2}$ ). Depending on the protocol, radiotherapy dose was between 14 and 36 grey units.

The most common abnormalities were azoospermia/ oligospermia in 64\% and endocrine abnormalities in $25 \%$ [Table 4]. Furthermore, $1 \%$ of the participants 
Table 1: Summary of characteristics of study population

\begin{tabular}{|c|c|c|}
\hline \multirow[t]{2}{*}{ Study characteristics } & \multirow[t]{2}{*}{ Category } & Descriptive statistics \\
\hline & & Percentage (number of patients) \\
\hline \multirow{4}{*}{$\begin{array}{l}\text { Age at the time of diagnosis } \\
\text { (years) }\end{array}$} & $<4$ & $20 \%(60)$ \\
\hline & $5-9$ & $44 \%(132)$ \\
\hline & $10-14$ & $26 \%(78)$ \\
\hline & $15-18$ & $10 \%(30)$ \\
\hline Gender & Males: Female ratio & 2.7 \\
\hline \multirow[t]{3}{*}{ Demographics } & Punjab & $77 \%(231)$ \\
\hline & Khyber Pakhtunkhwa & $20 \%(60)$ \\
\hline & $\begin{array}{l}\text { Other (baluchistan, Gilgit-Baltistan } \\
\text { and sindh) }\end{array}$ & $3 \%(9)$ \\
\hline $\begin{array}{l}\text { Median age at the time of last } \\
\text { follow-up (years) }\end{array}$ & & 18 (range: 10-25) \\
\hline
\end{tabular}

Table 2: Summary of distribution of the primary diagnosis in our study participants

\begin{tabular}{l|c}
\hline Diagnosis & Prevalence $\boldsymbol{n = 3 0 0 ( \% )}$ \\
\hline Hodgkin lymphoma & $50(150)$ \\
\hline Acute lymphoblastic leukaemia & $17(51)$ \\
\hline Non-Hodgkin lymphoma & $13(39)$ \\
\hline Germ cells tumour & $10(30)$ \\
\hline Retinoblastoma & $5(15)$ \\
\hline Others & $5(15)$ \\
\hline
\end{tabular}

Table 3: Summary of treatment combinations that were given to the study participants for management of primary disease

\begin{tabular}{l|c}
\hline Treatment combination & Prevalence $\boldsymbol{n = 3 0 0 ~ ( \% ) ~}$ \\
\hline Chemotherapy alone & $57(171)$ \\
\hline $\begin{array}{l}\text { Chemotherapy and radiother- } \\
\text { apy }\end{array}$ & $23(67)$ \\
\hline Chemotherapy and surgery & $15(46)$ \\
\hline $\begin{array}{l}\text { Chemotherapy, surgery and } \\
\text { radiotherapy }\end{array}$ & $3(10)$ \\
\hline Surgery alone & $2(6)$ \\
\hline
\end{tabular}

developed secondary malignancy (acute myeloid leukaemia and myelodysplastic). Thirty-three percent of the participants were studying in college or university, $7 \%$ of the participants were working, $4.6 \%$ of the participants were married and $2.9 \%$ of the participants had children.
Table 4: Number and percentages of late morbidities detected in the long-term follow of our study participants

\begin{tabular}{l|l|l}
\hline $\begin{array}{l}\text { Screening } \\
\text { test }\end{array}$ & $\begin{array}{l}\text { Number of } \\
\text { participants }\end{array}$ & $\begin{array}{l}\text { Outcome response } \\
(\%)\end{array}$ \\
\hline Semen analysis & 85 & Azoospermia (49) \\
\cline { 2 - 3 } & Oligospermia (15) \\
\hline $\begin{array}{l}\text { Thyroid func- } \\
\text { tion tests }\end{array}$ & 116 & Hypothyroidism (13.5) \\
\hline Audiometry & 46 & Ototoxicity (6.5) \\
\hline $\begin{array}{l}\text { Pulmonary } \\
\text { function tests }\end{array}$ & 181 & $\begin{array}{l}\text { Impaired diffusing lung } \\
\text { capacity for carbon } \\
\text { monoxide (4.6) }\end{array}$ \\
\hline $\begin{array}{l}\text { Echocardiog- } \\
\text { raphy }\end{array}$ & 83 & Cardiomyopathy (2.4) \\
\hline
\end{tabular}

Hypothyroidism was seen only in patients who received radiotherapy to the neck region. Ototoxicity was seen only in patients who received platinum-based chemotherapy as part of their treatment protocol. Pulmonary toxicity was seen only in patients who received bleomycin containing chemotherapy. Azoospermia/oligospermia was reported in patients who received procarbazine containing chemotherapy like CHLVPP/ABVD. Thirteen percent of the patients experienced single organ loss secondary to surgery in curative intent. In our cohort, unilateral enucleation was reported in $3.2 \%$, nephrectomy in $1.9 \%$, orchidectomy in 
$1.9 \%$ and oophorectomy in $4.2 \%$. We did not find any association between the rate of adverse effects and the demography of our patients $(P=0.2)$.

\section{Discussion}

It is estimated that one out of every 750 adults living today in the United States is a survivor of childhood cancer and that around $2 / 3^{\text {rd }}$ of all patients still living 30 years after their cancer treatment in childhood suffer from late complications. ${ }^{[20]}$ A study regarding multiple system abnormalities in long-term survivors by Livinalli et al. from Brazil found that $27.4 \%$ of the patients had abnormal test results observed in any one system, including $47 \%$ in the endocrine and metabolic, $41.2 \%$ in the cardiovascular (including but not limited to cardiomyopathy), $29.4 \%$ in the musculoskeletal and $5.9 \%$ in auditory and renal systems. ${ }^{[21]}$ Radiotherapy and alkylating agents have long been recognized as risk factors for second malignancies with a frequency of $3-7 \% .{ }^{[22-27]}$ In our cohort, 3\% of the patients experienced a relapse of primary disease and $1 \%$ of the patients developed another malignancy (acute myeloid leukaemia/myelodysplastic syndrome). All of these patients had received alkylating agents and radiotherapy as part of their treatment. Azoospermia/oligospermia was noted in 64\% in our review which corresponds to reports by Wasilewski-Masker et al. who found infertility in $46 \%$ of patients of long-term survivors of childhood cancer and Niels et al. who found subnormal levels of inhibin B in 67\%. ${ }^{[28,29]}$ Inhibin B level was used as a surrogate marker for spermatogenesis in their study. We could not determine infertility in our patients because the majority of our patients were unmarried, and it is considered inappropriate in the local culture to ask patients to undergo fertility testing. We used azoospermia/ oligospermia coupled with FSH as an indicator of deficient spermatogenesis instead of inhibin B. Alkylating agents, especially procarbazine and cyclophosphamide, are implicated in the causation of abnormalities in sperm count or morphology in published literature. ${ }^{[30,31]}$ In our review, out of the $64 \%$ having azoospermia and oligospermia, 72\% received procarbazine and/or cyclophosphamide in their primary treatment, confirming the gonadal damage caused by these two agents. A study by Ramjaun et al. found that $14.7 \%$ long-term survivors of childhood cancer had echocardiographic evidence of myocardial dysfunction. ${ }^{[32]}$ Mulrooney et al. reported cardiomyopathy in $7.4 \%$ cases of long-term survivors. ${ }^{[33]}$ An ongoing continual increase in the incidence of sustained echocardiographic abnormality was seen among patients treated with $>250 \mathrm{mg} / \mathrm{m}^{2}$ doxorubicin at age $<5$ years, reaching $43 \%$ by 20 years of therapy. Hu et al. found cardiotoxicity in 1.5\% recipients of anthracycline and reported that cumulative doses above $200 \mathrm{mg} / \mathrm{m}^{2}$ correlated with the emergence of cardiotoxicity in these patients. ${ }^{[34]}$ All of our patients who developed cardiomyopathy had received anthracyclines, but only $2.4 \%$ of the total percentage of these patients had echocardiographic abnormalities. Most of the patients were symptomatic with echocardiographic abnormalities and they were referred to cardiologist. This is lower than what is reported in the published literature probably due to the lesser cumulative doses of anthracyclines in our cohort as it was $<100 \mathrm{mg} / \mathrm{m}^{2}$ in 150 patients and only five patients received doses over $400 \mathrm{mg} /$ $\mathrm{m}^{2}$. Furthermore, another reason for lesser cardiac toxicity in our report may be shorter duration of follow-up as compared to studies mentioning greater cardiac toxicity with 20 years or more follow-up.

Kasteler et al. reported an increased incidence of pulmonary complications in survivors of childhood cancers. ${ }^{[35]}$ Bleomycin and radiotherapy to chest region are well-known risk factors implicated in lung damage or abnormal pulmonary function tests in long-term survivors. ${ }^{[36]}$ The majority of our patients $(90 \%)$ with impaired DLCO had received bleomycin and radiotherapy for Hodgkin lymphoma. In our report, the lung toxicity was comparable to other studies. ${ }^{[36]}$

Endocrine abnormalities are more common in long-term survivors of cancers than the general population, especially among those who received 
radiotherapy to anatomic regions in close proximity to endocrine glands. ${ }^{[6,37]}$ Endocrine hormone abnormalities reported in our report $(25 \%)$ are in agreement with other international studies. Sklar et al. reported thyroid abnormalities in $34 \%$ of the patients with Hodgkin lymphoma, $79 \%$ of whom received radiotherapy as part of multimodality treatment. ${ }^{[37]}$ Radiotherapy to the neck region causes direct damage to the thyroid gland. ${ }^{[38]}$ We agree with this finding as $30 \%$ of cases with hypothyroidism in our cohort occurred in Hodgkin lymphoma survivors who were given radiotherapy to the neck region. $\mathrm{LH}$ and FSH are affected in those who either receive cranial or testicular irradiation or orchidectomy as part of their treatment. ${ }^{[6]}$

Cisplatin is a commonly prescribed component of chemotherapy for germ cell tumours. It has been associated with permanent bilateral hearing loss in $10-75 \%$ of cases depending on the cumulative dose. ${ }^{[39]}$ In our tested cohort, $6.5 \%$ had hearing impairment and among them $50 \%$ received cisplatin.

Organ loss in the form of amputative limb surgery, orchidectomy, nephrectomy and enucleation has three-fold morbidity. It has physiological, physical and psychological implications for the long-term survivors. ${ }^{[40]}$ A study of 62 survivors of childhood acute lymphoblastic leukaemia and lymphoma reported selective neurocognition deficits rather than generalized cognitive dysfunction in these patients. ${ }^{[41]}$ The occurrence of $1.3 \%$ of hepatitis $B$ and/or $C$ in our patients appears to be multifactorial. It can be partly explained by frequent blood transfusion needs and the immunocompromised status of this subset of patients.

To date, no scientific evidence exists that genetic and ethnic background correlates with outcomes in long-term cancer survivors. ${ }^{[42]}$ However, a genetic component is postulated to play a role in the appearance of long-term adverse effects as the toxicity anchored by chemotherapeutic agents and radiotherapy is heterogeneous and non-linear. A study by Clemens et al. is assessing genetic determinants of ototoxicity during and after childhood cancer treatment, the results of their study are not yet available. ${ }^{[43]}$ Results of another analysis by Van der Kooi et al. regarding the genetic variation in gonadal impairment in female survivors of childhood cancer are awaited. ${ }^{[44]}$ Health insurance plays a pivotal role in ensuring the attendance of LTF clinics in cancer survivors. We did not perform genetic analysis of our patients who experienced toxicities due to the cost as testing were not available at our centre during the study period. Unfortunately, in low-income countries, the health insurance system is not well established. A study from the United States found a positive correlation between attendance in LTF clinics, and therefore early detection of adverse sequelae and insurance status of the patients. ${ }^{[45]}$ In a multivariate analysis, Klosky et al. concluded that the absence of insurance correlated with an increased loss to LTF in cancer survivors. ${ }^{[46]}$ Patients who experienced long-term complications in our cohort were referred to respective subspecialties for treatment. Patients who had amputation limb surgery were rehabilitated with prosthetic limbs and patients who had enucleation were offered prosthetic eye.

Our study had inherited limitations of a retrospective study design. We analysed limited parameters (due to cost) in long-term survivors in selected types of cancers (data were available only for the types of cancers treated at our centre). Psychological assessment and intelligence quotient were not calculated. In addition, the number of patients from Khyber Pakhtunkhwa was small and therefore the positive or negative impact of demography on adverse late effects among long-term survivors had limited significance in our review.

We conclude that a significant proportion of longterm survivors of childhood cancer experience health-related issues due to primary cancer and its treatment. The association of ethnic and genetic factors with the appearance of complications in these patients requires further studies. Regular follow-up is suggested in cancer centres to screen patients for the expected complications which are 
partly explained by the type and agents used as treatment modality. Mobilization of social services may help improve the attendance of cancer survivors in long-term follow-up.

\section{Acknowledgments}

There are no acknowledgments.

\section{References}

1. Ward E, DeSantis C, Robbins A, Kohler B, Jemal A. Childhood and adolescent cancer statistics, 2014. CA Cancer J Clin 2014;64:83-103.

2. Friedman DL, Meadows AT. Late effects of childhood cancer therapy. Pediatr Clin North Am 2002;49:1083-6.

3. Wolden SL, Chen L, Kelly KM, Herzog P, Gilchrist GS, Thomson J, et al. Long-term results of CCG 5942: A randomized comparison of chemotherapy with and without radiotherapy for children with Hodgkin's lymphoma-a report from the children's oncology group. J Clin Oncol 2012;30:3174-80.

4. Robison LL, Hudson MM. Survivors of childhood and adolescent cancer: Life-long risks and responsibilities. Nat Rev Cancer 2014;14:61-70.

5. Sloan FA, Gelband $H$. The cancer burden in low-and middle-income countries and how it is measured. In: Cancer Control Opportunities in Low-and MiddleIncome Countries 2007. United States: National Academies Press; 2007.

6. Cairo MS, Gerrard M, Sposto R, Auperin A, Pinkerton CR, Michon J, et al. Results of a randomized international study of high-risk central nervous system B non-Hodgkin lymphoma and B acute lymphoblastic leukemia in children and adolescents. Blood 2007; 109:2736-43.

7. Gerrard M, Cairo MS, Weston C, Auperin A, Pinkerton $R$, Lambilliote $A$, et al. Excellent survival following two courses of COPAD chemotherapy in children and adolescents with resected localized B-cell non-Hodgkin's lymphoma: Results of the $\mathrm{FAB} / \mathrm{LMB} 96$ international study. $\mathrm{Br} \mathrm{J}$ Haematol 2008;141:840-7.

8. Hann I, Vora A, Harrison G, Harrison C, Eden O, Hill F, et al. Determinants of outcome after intensified therapy of childhood lymphoblastic leukaemia: Results from medical research council United Kingdom acute lymphoblastic leukaemia XI protocol. Br J Haematol 2001;113:103-14.

9. Vora A, Goulden N, Wade R, Mitchell C, Hancock J, Hough R, et al. Treatment reduction for children and young adults with low-risk acute lymphoblastic leukaemia defined by minimal residual disease (UKALL 2003): A randomised controlled trial.
Lancet Oncol 2013;14:199-209.

10. Friedman DL, Himelstein B, Shields CL, Shields JA, Needle M, Miller D, et al. Chemoreduction and local ophthalmic therapy for intraocular retinoblastoma. J Clin Oncol 2000;18:12-7.

11. Mann JR, Raafat F, Robinson K, Imeson J, Gornall P, Phillips $M$, et al. UKCCSG's germ cell tumour (GCT) studies: Improving outcome for children with malignant extracranial non-gonadal tumourscarboplatin, etoposide, and bleomycin are effective and less toxic than previous regimens. United Kingdom children's cancer study group. Med Pediatr Oncol 1998;30:217-27.

12. Graf N, Tournade MF, de Kraker J. The role of preoperative chemotherapy in the management of Wilms' tumor: The SIOP studies. International society of pediatric oncology. Urol Clin North Am 2000;27:443-54.

13. Green DM. The treatment of stages I-IV favorable histology Wilms' tumor. J Clin Oncol 2004;22:1366-72.

14. Körholz D, Hamish W. Radiotherapy Manual; 2020. Available from: https://www.skion.nl/workspace/ uploads/euronet-phl-c1_workingcopy_inkl_ amendm06_mw_2012-11-14_0.pdf. [Last accessed on 2020 May 01].

15. Hann I, Vora A, Richards S, Hill F, Gibson B, Lilleyman J, et al. Benefit of intensified treatment for all children with acute lymphoblastic leukaemia: Results from MRC UKALL XI and MRC ALL97 randomised trials. UK medical research council's working party on childhood leukaemia. Leukemia 2000;14:356-63.

16. Coppes MJ, Wolff JE, Ritchey ML. Wilms tumour: Diagnosis and treatment. Paediatr Drugs 1999;1:251-62.

17. World Health Organization. Prevention of Blindness and Deafness: Grades of Hearing Impairment. Geneva: World Health Organization; 2011. Available from: http://www.who.int/pbd/deafness/hearing_ impairment_grades/en/index.html. [Last accessed on 2011 July 01].

18. Maclntyre N, Crapo R, Viegi G, Johnson DC, van der Grinten CP, Brusasco V, et al. Standardisation of the single-breath determination of carbon monoxide uptake in the lung. Eur Respir J 2005;26:720-35.

19. Kapelari K, Kirchlechner C, Högler W, Schweitzer K, Virgolini I, Moncayo R. Pediatric reference intervals for thyroid hormone levels from birth to adulthood: A retrospective study. BMC Endocr Disord 2008;8:15.

20. Langer T, Grabow D, Steinmann D, Wörmann B, Calaminus $G$. Late effects and long-term followup after cancer in childhood. Oncol Res Treat 2017;40:746-50.

21. Livinalli A, Silva MT, Lopes LC. Late adverse effects related to treatment in a cohort of survivors of childhood and adolescent cancer. Medicine (Baltimore) 2019;98:e14921.

22. Travis LB, Hill DA, Dores GM, Gospodarowicz M, 
van Leeuwen FE, Holowaty $E$, et al. Breast cancer following radiotherapy and chemotherapy among young women with Hodgkin disease. JAMA 2003;290:465-75.

23. Temming $P$, Arendt $M$, Viehmann A, Eisele $L$, Le Guin $\mathrm{CH}$, Schündeln MM, et al. Incidence of second cancers after radiotherapy and systemic chemotherapy in heritable retinoblastoma survivors: A report from the German reference center. Pediatr Blood Cancer 2017;64:71-80.

24. Chojnacka M, Pędziwiatr K, Skowrońska-Gardas A, Perek-Polnik M, Perek D, Olasek P. Second brain tumors following central nervous system radiotherapy in childhood. Br J Radiol 2014;87:20140211.

25. Friedman DL, Whitton J, Leisenring W, Mertens AC, Hammond S, Stovall M, et al. Subsequent neoplasms in 5-year survivors of childhood cancer: The childhood cancer survivor study. J Natl Cancer Inst 2010;102:1083-95.

26. Teepen JC, Kremer L, Ronckers CM, Van Leeuwen FE, Hauptmann M, Broeder VD, et al. Long-term risk of subsequent malignant neoplasms after treatment of childhood cancer in the DCOG LATER study cohort: Role of chemotherapy. J Clin Oncol 2017;35:2288-98.

27. Maule M, Scélo G, Pastore G, Brennan P, Hemminki K, Tracey $\mathrm{E}$, et al. Risk of second malignant neoplasms after childhood leukemia and lymphoma: An international study. J Natl Cancer Inst 2007;99:790-800.

28. Wasilewski-Masker K, Seidel KD, Leisenring W, Mertens AC, Shnorhavorian M, Ritenour CW, et al. Male infertility in long-term survivors of pediatric cancer: A report from the childhood cancer survivor study. J Cancer Surviv 2014;8:437-47.

29. van Casteren NJ, van der Linden GH, HakvoortCammel FG, Hählen K, Dohle GR, van den HeuvelEibrink MM. Effect of childhood cancer treatment on fertility markers in adult male long-term survivors. Pediatr Blood Cancer 2009;52:108-12.

30. Da Cunha MF, Meistrich ML, Fuller LM, Cundiff JH, Hagemeister FB, Velasquez WS, et al. Recovery of spermatogenesis after treatment for Hodgkin's disease: Limiting dose of MOPP chemotherapy. J Clin Oncol 1984;2:571-7.

31. Buchanan JD, Fairley KF, Barrie JU. Return of spermatogenesis after stopping cyclophosphamide therapy. Lancet 1975;306:156-7.

32. Ramjaun A, AIDuhaiby E, Ahmed S, Wang L, Yu E, Nathan PC, et al. Echocardiographic detection of cardiac dysfunction in childhood cancer survivors: How long is screening required? Pediatr Blood Cancer 2015;62:2197-203.

33. Mulrooney DA, Armstrong GT, Huang S, Ness KK, Ehrhardt MJ, Joshi VM, et al. Cardiac outcomes in adult survivors of childhood cancer exposed to cardiotoxic therapy: A cross-sectional study from the St. Jude lifetime cohort. Ann Intern Med 2016;164:93-101.

34. Hu H, Zhang W, Huang D, Yang Q, Li J, Gao Y. Cardiotoxicity of anthracycline (ANT) treatment in children with malignant tumors. Pediatr Hematol Oncol 2018;35:111-20.

35. Kasteler R, Weiss A, Schindler M, Sommer G, Latzin P, von der Weid NX, et al. Long-term pulmonary disease among Swiss childhood cancer survivors. Pediatr Blood Cancer 2018;65:e26749.

36. Huang TT, Hudson MM, Stokes DC, Krasin MJ, Spunt SL, Ness KK. Pulmonary outcomes in survivors of childhood cancer: A systematic review. Chest 2011;140:881-901.

37. Sklar C, Whitton J, Mertens A, Stovall M, Green D, Marina N, etal.Abnormalities of the thyroid in survivors of Hodgkin's disease: Data from the childhood cancer survivor study. J Clin Endocrinol Metab 2000;85:3227-32.

38. Vogelius IR, Bentzen SM, Maraldo MV, Petersen PM, Specht L. Risk factors for radiationinduced hypothyroidism: A literature-based metaanalysis. Cancer 2011;117:5250-60.

39. Travis LB, Fossa SD, Sesso HD, Frisina RD, Herrmann DN, Beard CJ, et al. Chemotherapyinduced peripheral neurotoxicity and ototoxicity: New paradigms for translational genomics. J Natl Cancer Inst 2014;106:dju044.

40. Shimoda S, Horsman J, Furlong W, Barr R, de Camargo B. Disability and health-related quality of life in long-term survivors of cancer in childhood in Brazil. J Pediatr Hematol Oncol 2008;30:563-70.

41. Bava L, Johns A, Kayser K, Freyer DR Cognitive outcomes among Latino survivors of childhood acute lymphoblastic leukemia and lymphoma: A crosssectional cohort study using culturally competent, performance-based assessment. Pediatr Blood Cancer 2018;65:e26844.

42. Clemens $E$, van der Kooi $A L$, Broer $L$, van Dulmenden Broeder $\mathrm{E}$, Visscher $\mathrm{H}$, Kremer $\mathrm{L}$, et al. The influence of genetic variation on late toxicities in childhood cancer survivors: A review. Crit Rev Oncol Hematol 2018;126:154-67.

43. Clemens E, Meijer AJ, Broer L, Langer T, van der Kooi AL, Uitterlinden AG, et al. Genetic determinants of ototoxicity during and after childhood cancer treatment: Protocol for the pancarelife study. JMIR Res Protoc 2019;8:e11868.

44. Van der Kooi AL, Clemens E, Broer L, Zolk O, Byrne J, Campbell H, et al. Genetic variation in gonadal impairment in female survivors of childhood cancer: A pan care life study protocol. BMC Cancer 2018;18:930.

45. Zheng DJ, Sint K, Mitchell HR, Kadan-Lottick NS. 
Patterns and predictors of survivorship clinic attendance in a population-based sample of pediatric and young adult childhood cancer survivors. J Cancer Surviv 2016;10:505-13.

46. Klosky JL, Cash DK, Buscemi J, Lensing S, GarcesWebb DM, Zhao W, et al. Factors influencing longterm follow-up clinic attendance among survivors of childhood cancer. J Cancer Surviv 2008;2:225-32.

\section{Authorship Contributions}

Conceived and designed the analysis; NS. Collected the data; NS, SR and MSK. Contributed data or analysis tools; SR and MSK. Performed the analysis; NS and MRJ. Wrote the paper; NS and MRJ. 